\title{
Zirconium(IV)-IMAC for phosphopeptide enrichment in phosphoproteomics
}

Ignacio Arribas Diez ${ }^{1}$, Ireshyn Govender ${ }^{2}$, Previn Naicker ${ }^{2}$, Stoyan Stoychev ${ }^{2,3}$, Justin Jordaan ${ }^{3,4}$, Ole N. Jensen $^{1}$

\author{
${ }^{1}$ Department of Biochemistry \& Molecular Biology and VILLUM Center for Bioanalytical Sciences, \\ University of Southern Denmark, DK-5230 Odense M, Denmark \\ ${ }^{2}$ NextGen Health, Council for Scientific and Industrial Research, Pretoria, South Africa \\ ${ }^{3}$ ReSyn Biosciences, Pretoria, Gauteng, South Africa \\ ${ }^{4}$ Rhodes University, Grahamstown, South Africa
}

Zr-IMAC for phosphopeptide enrichment in phosphoproteomics

Keywords: IMAC, MOAC, protein phosphorylation, affinity enrichment, magnetic particles, mass spectrometry, functional proteomics, cell signalling 


\section{Zr-IMAC for phosphopeptide enrichment in phosphoproteomics}

\section{ABBREVIATIONS}

Acetic acid: AcA

Acetonitrile: $\mathrm{MeCN}$

Ammonium bicarbonate: $A B C$

Data-dependent adquisition: DDA

Formic acid: FA

Glycolic acid: GA

Higher-energy collisional dissociation: HCD

Immobilized Metal ion Affinity Chromatography: IMAC

lodoacetamide: IAA

Mascot Generic File: mgf

Metal Oxide Affinity Chromatography: MOAC

Phosphopeptides: p-pep

Sodium deoxycholate: SDC

Solvent $1 / 2 / 3 / 4 / 5:$ S1/S2/S3/S4/S5

Tartaric acid: TA

Titanium: Ti

Titanium oxide: $\mathrm{TiO}_{2}$

Tris(2-carboxyethyl)phosphine hydrochloride: TCEP 
bioRxiv preprint doi: https://doi.org/10.1101/2020.04.13.038810; this version posted April 13, 2020. The copyright holder for this preprint (which was not certified by peer review) is the author/funder, who has granted bioRxiv a license to display the preprint in perpetuity. It is made available under aCC-BY-NC-ND 4.0 International license.

\section{Zr-IMAC for phosphopeptide enrichment in phosphoproteomics}

Zirconium: Zr

2-Chloroacetamide: CAA 
Zr-IMAC for phosphopeptide enrichment in phosphoproteomics

\section{ABSTRACT}

Phosphopeptide enrichment is an essential step in large-scale, quantitative phosphoproteomics studies by mass spectrometry. Several phosphopeptide affinity enrichment techniques exist, such as Immobilized Metal ion Affinity Chromatography (IMAC) and Metal Oxide Affinity Chromatography (MOAC). We compared Zirconium (IV) IMAC (Zr-IMAC) magnetic microparticles to more commonly used Titanium (IV) IMAC (Ti-IMAC) and TiO 2 magnetic microparticles for phosphopeptide enrichment from simple and complex protein samples prior phosphopeptide sequencing and characterization by mass spectrometry (LC-MS/MS). We optimized sampleloading conditions to increase phosphopeptide recovery for Zr-IMAC, Ti-IMAC and TiO ${ }_{2}$ based workflows. The performance of Zr-IMAC was enhanced by 19-22\% to recover up to 5173 phosphopeptides from $200 \mu \mathrm{g}$ of protein extract from HepG2/C3A cells, making Zr-IMAC the preferred method for phosphopeptide enrichment in this study. Ti-IMAC and $\mathrm{TiO}_{2}$ performance were also optimized to improve phosphopeptide numbers by $28 \%$ and $35 \%$, respectively. Furthermore, Zr-IMAC based phosphoproteomics in the magnetic microsphere format identified 23\% more phosphopeptides than HPLC-based Fe(III)-IMAC for same sample amount (200 $\mu \mathrm{g})$, thereby adding 37\% more uniquely identified phosphopeptides. We conclude that Zr-IMAC improves phosphoproteome coverage and recommend that this affinity enrichment method should be more widely used in biological and biomedical studies of cell signalling and in the search for disease-biomarkers. 


\section{Zr-IMAC for phosphopeptide enrichment in phosphoproteomics}

\section{INTRODUCTION}

Reversible protein phosphorylation regulates multiple processes in the cell, such as cell differentiation, metabolism, apoptosis and growth[1-3]. The reversible protein phosphorylation process is controlled by protein kinases that add the phosphate group to e.g. serine, threonine or tyrosine amino acid residues, and protein phosphatases that remove phosphate groups from amino acid side chains[3]. Alterations or dysregulation of these protein phosphorylation mechanisms can cause severe diseases such as cancer $[4-6]$, diabetes $[7,8]$ and neuronal disorders $[9,10]$. Therefore, therapeutics that target phosphoproteins and protein kinases have become important tools for battling these illnesses[11, 12].

Mass spectrometry (MS) is a key technology for defining the proteome, identifying new biomarkers and understanding cellular and molecular regulatory mechanisms. MS is the preferred bioanalytical method for indepth analysis of post-translational modifications of proteins [13], and it is indispensable for profiling and quantifying the dynamic phosphoproteome [14-16]. MS based phosphoproteomics strategies rely on efficient enrichment of phosphopeptides ( $p$-pep) since transient protein phosphorylation events frequently occur at low stoichiometry [14, 17]. Commonly used p-pep affinity enrichment techniques include anti-pTyr/pSer/pThr antibodies [18-20], pTyr-superbinders [21], immobilized metal ion affinity chromatography (IMAC) and metal oxide affinity chromatography (MOAC). IMAC uses metal cations, and MOAC metal oxides, that interact with the oxygen atoms of phosphate groups in peptides [17, 22, 23]. More recently, molecularly imprinted polymers (MIPs) have emerged as potential tools for selective phosphopeptide enrichment [24].

IMAC often employs $\mathrm{Fe}^{3+}$ as the phosphate-chelating ion species [25], but $\mathrm{Ga}^{3+}, \mathrm{Ti}^{4+}$ and $\mathrm{Zr}^{4+}$ are viable alternatives [26-29]. Particularly, $\mathrm{Ti}^{4+}$ has gained increased utility in recent years, i.e. Ti-IMAC [30-32]. $\mathrm{TiO}_{2}$ is the preferred reagent for MOAC based methods [33, 34], but other metal oxides have been tested, including $\mathrm{Al}_{2} \mathrm{O}_{3}, \mathrm{Fe}_{2} \mathrm{O}_{3}$ and $\mathrm{ZrO}_{2}$ [35-37]. Previous studies compared the efficiency of Fe-IMAC, Ti-IMAC, $\mathrm{TiO}_{2}$ and $\mathrm{ZrO}_{2}$ for phosphopeptide enrichment [38-41], demonstrating complementarity between these approaches and that their combination may increase the coverage of the phosphoproteome. 


\section{Zr-IMAC for phosphopeptide enrichment in phosphoproteomics}

Zirconium was first employed for phosphoproteomics in 2006 as $\mathrm{ZrO}_{2}$ [37] and soon after as $\mathrm{Zr}^{4+}$ phosphonate for enrichment and MALDI MS analysis of phosphopeptides [42]. A year later, Feng et al. published the first off-line ZrIMAC method for p-pep LC-MS/MS analysis [26]. Since then, Zirconium has been utilised in different formats, such as magnetic core silica nanoparticles [43], monolith columns[44], zirconium arsenate-based materials [35, 45] and aerogels [46]. Studies of $\mathrm{Zr}$ based techniques focused on $\mathrm{ZrO}_{2}$ and their performance were usually compared to $\mathrm{TiO}_{2}[37,47-49]$. Furthermore, $\mathrm{Zr}-\mathrm{IMAC}$ materials were compared to $\mathrm{ZrO}_{2}$ or Fe-IMAC [26, 43], showing higher selectivity than Fe-IMAC and improved stability against salt-containing solvents in the context of strong cation exchange $(\mathrm{SCX})$ chromatography separation of peptides. Despite these promising reports, $\mathrm{Zr}$-based affinity enrichment techniques have been overshadowed by the widely used $\mathrm{TiO}_{2}$ and $\mathrm{Ti}-\mathrm{IMAC}$ approaches in phosphoproteomics $[31,50]$.

Zirconium is a transition metal from group 4 in the periodic table, i.e. the same group as Titanium. Thus, $\mathrm{Zr}$ has very similar properties as $\mathrm{Ti}$, but with distinct differences. Both $\mathrm{Zr}$ and $\mathrm{Ti}$ can oxidize to state four (IV), producing salts of $\mathrm{ZrO} 2$ and $\mathrm{TiO}_{2}$ that strongly interact with oxygen anions. $\mathrm{Zr}$ is heavier than $\mathrm{Ti}$ (91.22 Da vs. $47.86 \mathrm{Da}$ ), making it a stronger Lewis acid, i.e. electron-pair acceptor, with a higher coordination number in the crystalline form ( 7 for $\mathrm{ZrO} 2$ and 6 for $\mathrm{TiO}_{2}$ ) [37, 51]. Since they are high-valence metal cations, both $\mathrm{Zr}$ and $\mathrm{Ti}$ have a unique coordination specificity with phosphates that allow binding of more than one phosphate group [52-54], making them both excellent candidates for phosphopeptide enrichment.

To our knowledge, a detailed comprehensive assessment of Zr-IMAC for phosphopeptide enrichment using complex biological samples is lacking. It remains to be established whether Zr-IMAC is a robust and efficient method for mass spectrometry based phosphoproteomics studies.

We hypothesized that Zr (IV) can perform similarly to Ti (IV) for phosphopeptide enrichment using polymer-based IMAC magnetic microparticles [31]. We also hypothesized that optimization of the protocols and reagents may improve performance for each of these methods, albeit not with the same specific conditions. 
bioRxiv preprint doi: https://doi.org/10.1101/2020.04.13.038810; this version posted April 13, 2020. The copyright holder for this preprint (which

was not certified by peer review) is the author/funder, who has granted bioRxiv a license to display the preprint in perpetuity. It is made available under aCC-BY-NC-ND 4.0 International license.

\section{Zr-IMAC for phosphopeptide enrichment in phosphoproteomics}

We therefore sought to improve phosphopeptide enrichment efficiency by adding hydroxy acids to the sample loading solvent, as hydroxy acids are known to improve the specificity and selectivity of phosphopeptide enrichment using IMAC and MOAC [48, 55]. We evaluated the effects of glycolic (GA), lactic (LA) and tartaric (TA) acids on p-pep enrichment using $\mathrm{Zr}$-IMAC, Ti-IMAC and $\mathrm{TiO}_{2}$ magnetic microparticles. Our optimized $\mathrm{Zr}$-IMAC protocol selectively and efficiently captures p-pep from microgram amounts of protein starting material obtained from biological samples. 


\section{Zr-IMAC for phosphopeptide enrichment in phosphoproteomics}

\section{EXPERIMENTAL PROCEDURES}

\section{Experimental design and statistical rationale}

A total of 36 digest ( $20 \mu \mathrm{g}$ each) of BSA + Casein were used for the optimization of binding solvent composition. Six separate enrichments were performed in technical duplicates with a different binding solvent (Std, S1, S2, S3, S4, S5, see Table 1) with three types of magnetic microparticles (Zr-IMAC, Ti-IMAC and $\mathrm{TiO}_{2}$ ). The standard binding solvent (Std) served as a control. $\mathrm{Zr}$-IMAC, $\mathrm{Ti}-\mathrm{IMAC}$ and $\mathrm{TiO}_{2}$ magnetic microparticles were evaluated in $\mathrm{n}=3$ technical replicates for phosphopeptide enrichment in two experimental binding solvent conditions: standard (Std) as the control and optimized (S1/ $\mathrm{TiO}_{2}$, S2/Zr-IMAC, S3/Ti-IMAC). In total, 36 samples of $200 \mu \mathrm{g}$ of HepG2/C3A human hepatocyte cells tryptic digest were used. For the comparison of optimized microparticles with Fe-IMAC HPLC, $n=4$ technical replicates of $200 \mu \mathrm{g}$ of HepG2/C3A human hepatocyte cells tryptic digest were enriched for $n$ $=5$ experimental conditions (total of 20 samples). Statistical tests used are described within each section.

\section{Materials and Chemicals}

All chemicals were obtained from Sigma Aldrich (Merck KGaA) unless otherwise stated. Ti(IV)-IMAC, $\operatorname{Zr}(I V)$-IMAC, and $\mathrm{TiO}_{2}$ ferromagnetic microparticles for phosphopeptide enrichment were from ReSyn Biosciences, RSA (Cat. no. MR-TIM002, MR-ZRM002 and MR-TID002). Kingfisher deep-well 96 plates were purchased from ThermoFisher Scientific. Sep-Pak tC18 3 cc Vacuum Cartridges were purchased from Waters Corp (Cat. no. WAT054925).

\section{Cell culture and lysis}

HepG2/C3A human hepatocyte cells (ATCC CRL-10741) were kindly provided by associate professor Adelina Rogowska-Wrzesinska and Helle Frandsen (University of Southern Denmark, Odense, DK). Cells were in standard culture conditions (87.5\% D-MEM (containing 1 g glucose/L) (Gibco), 1\% Non-Essential Amino Acids (Gibco), 10\% FCS (Foetal calf serum), 0.5\% Penicillin/Streptomycin (Gibco), $1 \%$ GlutaMAX (Gibco), $37^{\circ} \mathrm{C}, 5 \% \mathrm{CO}_{2} 95 \%$ air) and, when needed, they were trypsinized for 3 min with 0.05\% Trypsin/EDTA (Gibco Cat. no. 15400-054), diluted 1:4 and sown out into falcon tubes or microtitre plates [56]. Cells were collected 5 days after trypsinization at $85 \%$ 


\section{Zr-IMAC for phosphopeptide enrichment in phosphoproteomics}

confluence at subculture 10 and washed 5 times with warm $\left(37^{\circ} \mathrm{C}\right)$ Hanks' Balanced Salt Solution (HBSS without Ca++ and Mg++, Gibco Cat. no. 14175-053). After removal of all the remaining HBSS, the samples were snap frozen in liquid nitrogen and stored at $-80^{\circ} \mathrm{C}$ until further processing.

Frozen cell pellets were thawed on ice and suspended with gentle pipetting in $5 \mathrm{~mL}$ of cold lysis buffer (1\% sodium deoxycholate (SDC), 100mM ammonium bicarbonate (ABC), 10mM Tris(2-carboxyethyl)phosphine hydrochloride (TCEP), 40mM 2-Chloroacetamide (CAA), $\mathrm{pH} 8.5$, one tablet per $20 \mathrm{~mL}$ cOmplete ${ }^{\mathrm{TM}}$ Protease Inhibitor Cocktail (Roche), 1 tablet per $10 \mathrm{~mL}$ PhosSTOPTM (Roche)), then ruptured with a probe sonicator model CL-18 (Qsonica) in an ice-bath for 5 cycles of $20 \mathrm{sec} 50 \%$ power and $20 \mathrm{sec}$ break. The liquid was then heated at $80{ }^{\circ} \mathrm{C}$ for $10 \mathrm{~min}$. Proteins were precipitated with acetone overnight and washed twice with ice cold $80 \%$ acetone. The pellet was resuspended in $5 \mathrm{~mL}$ of $1 \% \mathrm{SDC}+50 \mathrm{mM} \mathrm{ABC} \mathrm{pH} 8.5$ and protein concentration was measured with Pierce $\mathrm{BCA}$ protein assay kit (Thermo Scientific). Samples were then aliquoted into $1.5 \mathrm{~mL}$ LoBind eppendorf tubes (Sorenson BioScience) and stored at $-80^{\circ} \mathrm{C}$ for future use.

Tryptic digestion of (phospho)protein samples

For the phosphopetide binding/elution solvent optimization experiments, a $5 \mathrm{mg}$ mixture of $\alpha$-, $\beta$ - and $\mathrm{k}$-Casein (Cat. no. C7078) and $5 \mathrm{mg}$ of Bovine Serum Albumin (BSA, Hyclone, Cat. no. SHB0574) were dissolved in $150 \mu$ and $200 \mu \mathrm{l}$, respectively, resuspension buffer (5.5M Guanidinium- $\mathrm{HCl}$ in $50 \mathrm{mM}$ Ammonium Bicarbonate (ABC), $50 \mathrm{mM}$ DTT) and heated at $35^{\circ} \mathrm{C}$ for $10 \mathrm{~min}$. Ten microliters of BSA solution were mixed with 30uL of Casein solution to a final concentration of $0.45 \mathrm{mg} / \mathrm{mL}$ and incubated at $60^{\circ} \mathrm{C}$ for $1 \mathrm{~h}$ for reduction, followed by $\mathrm{S}$-alkylation with $10 \mathrm{uL}$ of $0.5 \mathrm{M} \mathrm{IAA}$ in $50 \mathrm{mM} \mathrm{ABC}$ and incubated at room temperature in the dark for $30 \mathrm{~min}$. The protein mixture was diluted to $25 \mathrm{mg} / \mathrm{ml}$ with $50 \mathrm{mM} \mathrm{ABC}$ and 500 ug of protein were digested with $2 \% \mathrm{w} / \mathrm{w}$ Trypsin (Promega, Cat. no. V5111) in $1 \mathrm{~mL}$ of $50 \mathrm{mM} \mathrm{ABC}$ overnight at $37^{\circ} \mathrm{C}$. Digestion was stopped with $10 \%$ formic acid $(F A)$ to a final concentration of $0.5 \% \mathrm{FA}$ and $45 \mathrm{uL}$ aliquots were stored at $-20^{\circ} \mathrm{C}$.

Cell lysate protein extracts were digested with in-house methylated [57] porcine Trypsin (Cat. no. T0303) at 2\% $\mathrm{w} / \mathrm{w}$ and incubated overnight at $37^{\circ} \mathrm{C}$. Tryptic digestion was terminated by adding trifluoroacetic acid (TFA) to $1 \%$ 


\section{Zr-IMAC for phosphopeptide enrichment in phosphoproteomics}

concentration. Digested samples were centrifuged for $5 \mathrm{~min}$ at $14,000 \mathrm{rpm}$ to precipitate the SDC and the supernatant liquid was transferred to a new tube. Peptide samples were then de-salted using Sep-Pak tC18 3 cc Vac Cartridges (Waters Corp, Cat. no. WAT054925). Cartridges were first conditioned with $2 \mathrm{~mL}$ of $95 \%$ acetonitrile (MeCN) / 0.1\% TFA and equilibrated with 2x 3mL 5\% MeCN / 0.1\% TFA. Peptide samples were then loaded and the cartridge was rinsed using $2 \times 3 \mathrm{~mL}$ of $5 \% \mathrm{MeCN} / 0.1 \%$ TFA. Elution was achieved by adding $3 \times 1 \mathrm{~mL} 50 \% \mathrm{MeCN} / 0.1 \%$ TFA. Eluted peptide samples were collected in $5 \mathrm{~mL}$ tubes. Peptide samples were dried using a vacuum centrifuge concentrator and stored at $-80^{\circ} \mathrm{C}$.

Phosphopeptide enrichment using polymer based magnetic microparticles

Optimization of sample loading conditions: $\mathrm{TiO}_{2}$, Ti-IMAC and $\mathrm{Zr}$-IMAC magnetic microparticles (ReSyn Biosciences) were tested in duplicate with the standard loading and binding solvent recommended by the manufacturers ( $80 \%$ MeCN, 5\% TFA, $1 \mathrm{M}$ glycolic acid (GA)) and five alternative solutions: $\mathrm{S} 1(50 \% \mathrm{MeCN}, 0.1 \%$ acetic acid (AcA), $0.1 \mathrm{M}$ GA), S2 (80\% MeCN, 5\% TFA, 0.1M GA), S3 (80\% MeCN, 5\% TFA, 0.1M lactic acid (LA)), S4 (80\% MeCN, 5\% TFA, 0.1M tartaric acid (TA)) and S5 (50\% MeCN, 0.1\% AcA, 0.1M TA).

Dried tryptic peptides were re-dissolved in $0.1 \%$ TFA to a concentration of $\sim 4 \mu \mathrm{g} / \mu \mathrm{L}$ and diluted to a final volume of 200uL with the corresponding binding solvent (S1-S5) for enrichment. Experiments performed at Council for Scientific and Industrial Research (CSIR, Pretoria, Republic of South Africa) employed a KingFisher Duo workstation (Thermo Scientific) for automated magnetic microsphere based phosphopeptide enrichment. The protocol was adapted for manual magnetic microsphere-based p-pep enrichment at the University of Southern Denmark (Odense, Denmark). The enrichment protocol was performed as previously described [31], maintaining a 1:2 peptide-to-beads weight ratio. In brief, the magnetic particles were first equilibrated with loading/binding solvent for $5 \mathrm{~min}$, followed by $20 \mathrm{~min}$ incubation with the peptide mixture (20 $\mu \mathrm{g}$ for Casein/BSA tryptic digests, $200 \mu \mathrm{g}$ for liver cell protein extracts). Microspheres were then washed for 2 min each, first with solvent (S1-S5, 500 $\mu \mathrm{L})$, then wash solvent $1(80 \% \mathrm{MeCN}+1 \% \mathrm{TFA}, 500 \mu \mathrm{L})$ and lastly by wash solvent $2(10 \% \mathrm{MeCN}+0.2 \% \mathrm{TFA}, 500 \mu \mathrm{L})$. Phosphopeptides were eluted from the microparticles by 10 min incubation in $1.25 \mathrm{M}$ of ammonium hydroxide 


\section{Zr-IMAC for phosphopeptide enrichment in phosphoproteomics}

solution $(200 \mu \mathrm{L})$. Total program time was 45 min and all incubation steps were done with continuous mixing to keep a homogenous bead suspension. Collected peptides were lyophilized and stored at -80 ㅇ $\mathrm{C}$ prior analysis.

For Zr-IMAC reproducibility experiments, Zr-IMAC and Ti-IMAC magnetic microbeads were tested in five replicates with the standard binding solvent and the optimized solvent S2. Enrichment protocol [31] was manually performed on a $96 \times 2 \mathrm{~mL}$ plate. A schematic visualization of the workflow can be seen in Figure 1B, right branch.

\section{Phosphopeptide enrichment with Fe-IMAC HPLC}

LC based Fe(III)-IMAC [38] was implemented using a ProPac ${ }^{\mathrm{TM}}$ Fe-NTA column (2x50 mm, Thermo Scientific) connected to a UPLC Ultimate 3000 system (Thermo Scientific) via an $800 \mu \mathrm{L}$ injection loop. The IMAC column was charged with iron (III) according to the manufacturer's instructions. Prior sample loading the column was equilibrated with $50 \%$ solvent $\mathrm{C}(100 \% \mathrm{MeCN})+50 \%$ solvent $\mathrm{A}\left(99.9 \% \mathrm{H}_{2} \mathrm{O}+0.1 \% \mathrm{TFA}\right)$. Approximately $200 \mu \mathrm{g}$ of tryptic protein digest was dissolved in $0.1 \%$ TFA to $4 \mathrm{ug} / \mu \mathrm{L}$ concentration and diluted to $710 \mathrm{uL} 50 \% \mathrm{MeCN}+0.1 \%$ TFA. Injection volume was $700 \mu \mathrm{L}$. After sample loading, the column was washed for 5 min with $50 \%$ solvent $\mathrm{C}+$ $50 \%$ solvent $A$ followed by $50 \%$ solvent $C+50 \%$ solvent $B\left(20 \mathrm{mM} \mathrm{NH}_{4} \mathrm{OH}\right)$ for 2 min. Phosphopeptides were collected with $100 \%$ solvent B for 2 min and the column was re-equilibrated with $50 \%$ solvent $C+50 \%$ solvent $A$ for 7 min. Peptides were dried using a vacuum centrifugal concentrator and stored at $-80^{\circ} \mathrm{C}$ prior LC-MS/MS analysis.

\section{MALDI-TOF MS analysis of peptides}

Phosphopeptide samples obtained by enrichment from Casein/BSA tryptic digests were re-suspended in 25uL of 0.1\% TFA. Two microliters of the peptide solution were mixed with $2 \mathrm{uL}$ of a 1:3:3 mixture of isotopically labelled ppep (VPQ[L_C13N15]EI[V_C13N15]PN[pSer]AEER (1662 Da), YKVPQLE[I_C13N15]VPN[pSer]AEER (1957 Da) and FQ[pSer]EEQQQTEDE[L_C13N15]QDK (2067 Da) (ThermoFisher Scientific, Supplementary Figure 1)) and 2uL of matrix solution $\left(30 \mathrm{mg} / \mathrm{mL} \mathrm{DHB}\right.$ in $50 \% \mathrm{MeCN}+1 \% \mathrm{H}_{3} \mathrm{PO}_{4}$ ), plated $1.8 \mathrm{uL}$ on a 384 ground-steel MALDI plate and once dried, re-crystallized with 0-5uL acetone. 


\section{Zr-IMAC for phosphopeptide enrichment in phosphoproteomics}

Peptides were analysed on a Bruker Autoflex MALDI-TOF MS instrument using positive ion reflector mode and a $\mathrm{m} / \mathrm{z}$ range of $1000-3500$. Pulsed ion extraction was $40 \mathrm{~ms}$ and a UV laser power of $30-45 \%$ were applied. Spectra corresponding to three hundred laser pulses were accumulated per acquisition. The signal for each $\mathrm{p}$-pep was normalised against the highest responding heavy internal standard (YKVPQLE[I_C13N15]VPN[pSer]AEER, m/z 1958) to quantify enrichment efficiency for each solvent composition. Experiments were analysed in duplicate.

\section{Phosphopeptide analysis by LC-MS/MS using Sciex TripleTOF 6600 system}

Dried phosphopeptides were dissolved in $10 \mathrm{uL}$ of $2 \% \mathrm{MeCN}+0.1 \% \mathrm{FA}$, vortexed for 1 min and centrifuged at $14,000 \mathrm{rpm}$ for $10 \mathrm{~min}$ to remove any residual particles. Peptides were analysed using a Dionex Ultimate 3000 RSLC system (Thermo Scientific) coupled online to a TripleTOF ${ }^{\circledR} 6600$ hybrid tandem mass spectrometer (Sciex). Injected peptide samples were on-line de-salted/concentrated using an Acclaim PepMap C18 trap column $(75 \mu \mathrm{m} \times 2 \mathrm{~cm}$, Thermo Scientific) for $2 \mathrm{~min}$ at $5 \mathrm{uL} / \mathrm{min}$ using $2 \% \mathrm{MeCN}+0.2 \% \mathrm{FA}$. Trapped peptides were gradient eluted and separated on an Acclaim ${ }^{\mathrm{TM}}$ PepMap ${ }^{\mathrm{TM}}$ C18 RSLC column $(75 \mu \mathrm{m} \times 15 \mathrm{~cm}, 2 \mu \mathrm{m}$ particle size, Thermo Scientific) at a flow-rate of $500 \mathrm{~nL} / \mathrm{min}$ with a linear gradient of $3 \%-40 \%$ solvent $B(80 \% \mathrm{MeCN}+0.1 \% \mathrm{FA})$ against solvent $\mathrm{A}$ (100\% $\mathrm{H}_{2} \mathrm{O}+0.1 \%$ FA). Eluted peptides were electrosprayed using a NanoSpray ${ }^{\circledR}$ III Ion Source (Sciex) with the following source settings: CUR - 10, GS1 - 24, GS2 - 0, HT - $80^{\circ} \mathrm{C}$ and ISVF - 2800.

LC-MS/MS was performed in the data-dependent acquisition (DDA) mode. Mass spectra were acquired in the range $m / z$ 400-1500 ( $2+$ to $5+$ charge states) using an accumulation time of 250 ms followed by 80 MS/MS events. MS/MS spectra were acquired for the range m/z 100-1800 at 25 ms accumulation time per spectrum. Minimum threshold for triggering MS/MS was set to $250 \mathrm{cps}$. Precursor ions were fragmented in the q2 collision cell using nitrogen as the collision gas. Collision energies were automatically defined as function of $\mathrm{m} / \mathrm{z}$ and charge state. Selected ions for MS/MS were dynamically excluded for $15 \mathrm{sec}$.

Phosphopeptide analysis by LC-MS/MS using Q-Exactive HF system

Dried phosphopeptides were handled as previously mentioned and analysed on a Dionex Ultimate 3000 RSLCnano system coupled online to a Q-Exactive ${ }^{\circledR} \mathrm{HF}$ hybrid quadrupole-orbitrap tandem mass spectrometer (Thermo 


\section{Zr-IMAC for phosphopeptide enrichment in phosphoproteomics}

Scientific). Injected peptides were on-line de-salted using a C18 PepMap ${ }^{\mathrm{TM}} 100$ trap column (300um i.d. x 5mm,

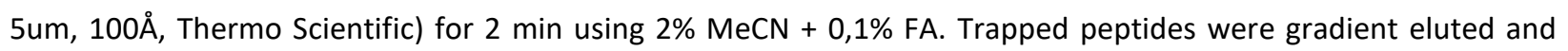
separated on a 75um i.d. x 30cm column packed inhouse with ReproSil-Pur 120 C18 1.9um particles (Dr. Maisch) at a flow-rate of $300 \mathrm{~nL} / \mathrm{min}$ with a linear gradient of $5 \%-35 \%$ solvent B ( $95 \% \mathrm{MeCN}+0.1 \% \mathrm{FA})$ against solvent $\mathrm{A}$ $\left(100 \% \mathrm{H}_{2} \mathrm{O}+0.1 \% \mathrm{FA}\right)$.

Precursor ion (MS) spectra were acquired in the range $\mathrm{m} / \mathrm{z} 300-2000(2+$ to $5+$ ion charge state) at a mass resolution setting of 60,000 at $\mathrm{m} / \mathrm{z} 400$ in profile mode, with an AGC target of $1 \mathrm{e} 5$ ions. The 20 most intense precursor ions were fragmented with higher-energy collisional dissociation (HCD) and dynamically excluded for 15 sec. Fragments were detected in the Orbitrap at a mass resolution setting of 30,000 at m/z 400 in centroid mode.

\section{LC-MS/MS Data analysis}

Prior data analysis, all wiff data files from Sciex TripleTOF ${ }^{\circledR} 6600$ were converted to Mascot Generic File (mgf) with ProteoWizard MSConvert (version 3.0.19137) with peak picking filtering for the 150 most intense peaks. Mgf files and raw files from the Q-Exactive ${ }^{\circledR} \mathrm{HF}$ were processed with Proteome Discoverer 2.3 (Thermo Scientific) and searched against SwissProt human database (February 2019 release) using Mascot 2.6 (Matrix Science) with 50 ppm precursor mass tolerance for mgf files and $10 \mathrm{ppm}$ for raw files. Fragment mass tolerance was set to $0.2 \mathrm{Da}$ for mgf files and 0.05 Da for raw files with a limit of 2 missed tryptic cleavages. S-carbamidomethylation of cysteine was set as a fixed modification while $O$-phosphorylation of serine, threonine, and tyrosine, and oxidation of methionine were set as variable modifications. Peptides were filtered using a Mascot ion score threshold of $\geq 18$ and a FDR of $\leq 0.01$ through Percolator [58]. Phosphorylation localization probabilities were calculated with ptmRS [59] and only probabilities $\geq 75 \%$ were accepted. Feature analysis of phosphopeptides was done using a custom made R script to calculate peptide hydrophobicity by Kyte \& Doolittle hydropathy indexes [60] and the pl values were obtained from the online protein isoelectric point calculator [61]. An Excel sheet was used to count the number of basic and acidic residues, as well as the total number of amino acids per sequence. Protein sequence 
bioRxiv preprint doi: https://doi.org/10.1101/2020.04.13.038810; this version posted April 13, 2020. The copyright holder for this preprint (which was not certified by peer review) is the author/funder, who has granted bioRxiv a license to display the preprint in perpetuity. It is made available under aCC-BY-NC-ND 4.0 International license.

\section{Zr-IMAC for phosphopeptide enrichment in phosphoproteomics}

visualization and phosphorylation site illustration was done on the General Protein/Mass Analysis for Windows software tool (GPMAW v. 11.0)[62].

The mass spectrometry proteomics data described in this manuscript have been deposited to the ProteomeXchange Consortium (http://www.proteomexchange.org) via the PRIDE partner repository [63] with the dataset identifier PXD018273. 


\section{Zr-IMAC for phosphopeptide enrichment in phosphoproteomics}

\section{RESULTS}

\section{Optimization of solvent composition for phosphopeptide enrichment by IMAC and MOAC}

Three magnetic bead chemistries (two IMAC, one MOAC) were tested with recommended solvents (Std) and five modified binding solvents (S1-S5) to identify the optimal bead-solvent combination (Table 1). Tryptic digests of Casein/BSA were used for these initial phosphopeptide enrichment experiments (Figure 1A). Zr-IMAC, Ti-IMAC and $\mathrm{TiO}_{2}$ microbeads were incubated in their corresponding binding solvents with the protein digests, followed by washing of the beads and elution of the p-pep with $1.25 \mathrm{M}$ ammonium hydroxide solution.

To quantify phosphopeptide recovery, the eluted fractions were mixed with three isotopically labelled phosphopeptides (Supplementary Figure 1) prior MALDI analysis, and the light phosphopeptide intensities were normalized to the most intense signal of the heavy labelled peptides (YKVPQLE[I_C13N15]VPN[pSer]AEER, m/z 1958). Figure 2 shows the relative intensities of identified phosphorylated sequences. In all cases, the addition of tartaric acid to the sample loading solvent (solvents S4 and S5, Figure 2) resulted in a significant decrease in phosphopeptide signal intensity in MALDI MS. Reducing the glycolic acid concentration from $1 \mathrm{M}$ to $0.1 \mathrm{M}$ (S2) enhanced the phosphopeptide signal intensity without major effects on specificity (Std vs S2, Figure 2). Also, 0.1M lactic acid (S3) improved phosphopeptide signal intensities without major effects on specificity (Std vs S3, Figure 2). For Ti-IMAC and Zr-IMAC, the very acidic solvents S2 and S3 (5\% trifluoroacetic acid) performed better than solvent S1 ( $0.1 \%$ Acetic acid) as seen by the higher intensity values obtained from most phosphopeptides (Figure 2 ). However, $\mathrm{TiO}_{2}$ showed augmented signal intensity when using solvent S1 at milder pH conditions (S1 vs. S2 and S3, Figure 2).

Relative phosphopeptide signal abundances were higher with S2/Zr-IMAC than with Std solvent (Figure 2), doubling the intensities of $\mathrm{p}-$ pep m/z 1660 and m/z 1951 and tripling the signal intensity at m/z 1539 (Figure 2, and data not shown). S3/Ti-IMAC and $\mathrm{S} 1 / \mathrm{TiO}_{2}$ showed similar results when compared to the Std solvent: $\mathrm{S}_{1} / \mathrm{TiO}_{2}$ 


\section{Zr-IMAC for phosphopeptide enrichment in phosphoproteomics}

improved by $2 x, 3 x$ and $5 x$ the ion signals of $p$-pep at $\mathrm{m} / \mathrm{z} 1660,1951,1832$, respectively, while S3/Ti-IMAC doubled that of $\mathrm{m} / \mathrm{z} 1539$.

Table 1. List of solvents used during phosphopeptide enrichment with magnetic microparticles.

\begin{tabular}{|l|l|l|}
\hline Solvent name & Enrichment step & Binding solvent composition \\
\hline Std & Binding/Washing & $80 \% \mathrm{MeCN}, 5 \%$ TFA, 1M GA \\
\hline S1 & Binding/Washing & $50 \% \mathrm{MeCN}, 0.1 \%$ Acetic, 0.1M GA \\
\hline S2 & Binding/Washing & $80 \% \mathrm{MeCN}, 5 \%$ TFA, 0.1m GA \\
\hline S3 & Binding/Washing & $80 \% \mathrm{MeCN}, 5 \%$ TFA, 0.1M LA \\
\hline S4 & Binding/Washing & $80 \% \mathrm{MeCN}, 5 \%$ TFA, 0.1M TA \\
\hline S5 & Binding/Washing & $50 \% \mathrm{MeCN}, 0.1 \%$ Acetic, 0.1M TA \\
\hline Wash 1 & Washing & $80 \% \mathrm{MeCN}, 1 \%$ TFA \\
\hline Wash 2 & Washing & $10 \% \mathrm{MeCN}, 0.2 \%$ TFA \\
\hline Elution & Elution & $1.25 \mathrm{M}$ Ammonium hydroxide \\
\hline
\end{tabular}

Based on these results, solvents S3, S2 and S1 were selected as optimal loading solvents for Ti-IMAC, Zr-IMAC and $\mathrm{TiO}_{2}$, respectively, and further tested by using complex peptide mixtures derived from cell extracts.

\section{Enrichment efficiency assessment using complex peptide mixtures}

Zr-IMAC, Ti-IMAC and $\mathrm{TiO}_{2}$ functionalized magnetic microparticles were tested for phosphopeptide enrichment using the standard and optimized solvent conditions. A complex sample consisting of a tryptic peptide mixture derived from human HepG2/C3A cells was used for automated phosphopeptide enrichment [31] on a KingFisher Duo workstation (Thermo Scientific). The enriched phosphopeptide eluates were analysed by LC-MS/MS on a Sciex TripleTOF 6600 and the raw files were processed for peptide identification using Proteome Discoverer and Mascot as the search engine (Figure 1B, left branch).

Changing the standard binding solvent to an optimized binding solvent (S1-S3) increased the number of identified phosphopeptides for all bead types (Figure 3A). Zr-IMAC retrieved more p-pep than Ti-IMAC and $\mathrm{TiO}_{2}$ in both standard (3900) and optimized (4624) conditions, respectively (Figure 3A). Moreover, S2/Zr-IMAC captured the highest number of p-pep (4624) followed by S3/Ti-IMAC (4042). S1/ $\mathrm{TiO}_{2}$ recovered a higher number of p-pep (2744) as compared to using the Std solvent (2039), albeit lower numbers than obtained by either Zr-IMAC or Ti- 


\section{Zr-IMAC for phosphopeptide enrichment in phosphoproteomics}

IMAC. Based on enumeration of retrieved and identified phosphopeptides, Zr-IMAC and Ti-IMAC outperformed $\mathrm{TiO}_{2}$ under standard conditions and optimized conditions, identifying almost twice the number of p-pep under Std solvent conditions (Figure 3A).

Next, we investigated the selectivity of each enrichment method for phosphopeptide enrichment (Figure 3A). ZrIMAC and Ti-IMAC showed over 97\% selectivity for p-pep as determined by the ratio: (number of identified p-pep) / (number of identified peptides + p-pep), while $\mathrm{TiO}_{2}$ selectivity was reduced to $82 \%$ when using S1 binding solvent (0.1\% Acetic acid) as compared to the Std control (98\%). This was to be expected, as the acidic environment in S1 was less harsh than Std binding solvent, allowing un-specific binding of carboxylate groups to the metal oxide of $\mathrm{TiO}_{2}$.

Notably, the optimized binding solvents altered the relative distribution of singly, doubly and multiply phosphorylated peptides for all three affinity enrichment chemistries, increasing the number of monophosphorylated peptides relative to di- and multi- phosphorylated peptides (Figure 3B). This effect was most pronounced for $\mathrm{TiO}_{2}$, and smaller for $\mathrm{Zr}$-IMAC and Ti-IMAC.

The overall improvement of phosphopeptide recovery by tailored and optimized binding solvent is shown in Figure 3C. The $\mathrm{TiO}_{2}$ method gained the most from the optimization, binding 35\% more p-pep when using $\mathrm{S} 1$ as compared to Std conditions, followed by S2/Zr-IMAC (19\% improvement) and S3/Ti-IMAC (5\% improvement).

Considering the protein level, optimized S2/Zr-IMAC protocol identified 1733 phosphoproteins, thereby exceeding all other methods and conditions that ranged from 930 to 1545 phosphoproteins (Supplementary Figure 2). TiIMAC identified a similar number of phosphorylated proteins (1499 and 1478, respectively) and sharing $85 \%$ of the total proteins with $\mathrm{Zr}$-IMAC. $\mathrm{TiO}_{2}$ identified the lowest number of phosphoproteins but gained the most proteins (34\%) from a change of solvent condition from Standard to S1. Ti-IMAC improved by 5\% more proteins by using solvent S3 rather than Std. Using the PANTHER GO-slim tool for genome classification [64] we analysed the identified proteins for the optimized methods on their cellular component to observe their proteome coverage (Supplementary Figure 3). All three materials presented the same distribution of protein classes: around $80 \%$ 


\section{Zr-IMAC for phosphopeptide enrichment in phosphoproteomics}

representing cell (GO:0005623) and organelle (GO:0043226), followed by $\sim 15 \%$ of protein-containing complexes (GO:0032991) and 3\% membrane proteins.

In total, 5173 phosphorylated peptides were identified by the combination of S2/Zr-IMAC, S3/Ti-IMAC and S1/ TiO 2 (Figure 4A). Almost half of these phosphopeptides (44\%) were recovered by all three methods (2278, Figure 4A). Some phosphopeptides were exclusively recovered by one method (S2/Zr-IMAC: 829/16\%; S3/Ti-IMAC: 270/5.2\%; S1/ $\mathrm{TiO}_{2}$ : 85/1.6\%; Figure 4A), which demonstrated that $\mathrm{Zr}$-IMAC contributes a significant number of additional phoshopeptides as compared to other methods. Furthermore, S2/Zr-IMAC recovered $89.3 \%$ of the total number of phosphopeptides (Figure 4A) identified by all methods, followed by S3/Ti-IMAC (79.7\%) and $\mathrm{TiO}_{2}(53 \%)$.

To understand the binding properties of each bead type and their potential complementarity, the number of method specific p-pep identified (S2/Zr-IMAC 829, S3/Ti-IMAC 270, S1/ $\mathrm{TiO}_{2} 85$, Figure 4A) were characterized according to their hydrophobicity, pl value and peptide length (Figure 4B). As a control, the same characteristics were analysed for all identified p-pep in each method (S2/Zr-IMAC 4624, S3/Ti-IMAC 4072, S1/ $\mathrm{TiO}_{2} 2744$, figure $4 C)$.

In figure $4 \mathrm{~B}$, the unique phosphopeptidesbound by $\mathrm{Ti}-\mathrm{IMAC}$ and $\mathrm{TiO}_{2}$ were longer than those recovered by $\mathrm{Zr}$-IMAC (median of 19, 20 and 16 amino acids (a.a.) respectively. Considering all phosphopeptides (Figure 4C), the length distribution of Ti-IMAC and $\mathrm{TiO}_{2}$ shifted to shorter sequences while $\mathrm{Zr}$-IMAC maintained a similar profile as for peptides (medians of 17,17 and 16 a.a. respectively).

The hydrophobicity curve of S2/Zr-IMAC was notably skewed to the right in Figure 4B and more subtly in Figure 4C, showing a higher affinity of $\mathrm{Zr}$-IMAC for hydrophobic sequences compared to the other methods, whereas $\mathrm{S} 1 / \mathrm{TiO}_{2}$ was skewed more to the left, i.e. a more hydrophilic preference.

The $\mathrm{pl}$ values of each condition highlighted a greater proportion of acidic sequences in $\mathrm{TiO}_{2}$ (Figure 4B and 4C, right) as a result of the less acidic environment. On the other hand, Zr-IMAC and Ti-IMAC had more similar profiles, though Zr-IMAC showed a more distributed proportion of its unique p-pep. 


\section{Zr-IMAC for phosphopeptide enrichment in phosphoproteomics}

The physical features of the uniquely found phosphopeptides from the standard and optimized solvents for each bead chemistry were also scrutinized (Supplementary Figure 4). More acidic and hydrophilic sequences bound to $\mathrm{TiO}_{2}$ when using the higher $\mathrm{pH}$ solvent $\mathrm{S} 1$ ( $0.1 \%$ Acetic acid) since the selectivity decreased and non-protonated carboxylated groups could interact with the metal oxide. This is also reflected by the decreased number of multiply phosphorylated peptides (Figure 3B) as a result of a more competitive environment. Changing $1 \mathrm{M}$ of Glycolic acid (Std) to either $0.1 \mathrm{M}$ of GA (S2) or $0.1 \mathrm{M}$ LA (S3) increased binding of more hydrophobic and basic peptides. This change in hydrophobicity could be affected by the number of phosphate groups in the peptides, as Std/Zr-IMAC unique peptides were mostly multi-phosphorylated while S2/Zr-IMAC had mostly mono-phosphorylated peptides (Supplementary figure 5). Furthermore, the average peptide length was lower in the optimized conditions compared to the standard for all chemistries.

\section{Comparison of optimized microparticles and solvents with Fe-IMAC HPLC}

Our previous results showed that Zr-IMAC recovered the highest number of phosphopeptides (4624) with the optimized solvent S2 (80\% MeCN + 5\% TFA + 0.1M GA). We hypothesised that S2 could improve Ti-IMAC microparticles performance on complex digests just as it did with Zr-IMAC. For this purpose, Zr-IMAC and Ti-IMAC magnetic microbeads were tested manually with both the standard (Std) and optimized (S2) conditions and compared with a well-known method for p-pep enrichment: Fe-IMAC (LC-format). Since Fe (III) ions have different chemical and coordination properties, like lower charge state and binding to just one supporting ligand (NTA)[51], we hypothesized that both magnetic materials would be more selective and capture higher numbers of $p$-pep than Fe-IMAC. The phosphopeptide enriched fractions were analysed by LC-MS/MS on a Q-Exactive HF mass spectrometer and the raw files were processed for peptide identification using Proteome Discoverer with Mascot as the search engine (Figure 1B, right branch).

The optimized enrichment with Zr-IMAC microparticles identified the highest number of phosphopeptides (5173), followed by S2/Ti-IMAC, Std/Zr-IMAC, Fe-IMAC HPLC and Std/Ti-IMAC (4433, 4249, 4199 and 3564, respectively, Figure 5A). All the enrichments performed with magnetic bead microparticles were highly selective towards $p$-pep 


\section{Zr-IMAC for phosphopeptide enrichment in phosphoproteomics}

with more than $90 \%$ of the total peptides assigned as phosphopeptides, while the selectivity of Fe-IMAC HPLC was significantly lower (78\%) in our hands.

As expected, changing the binding solvent to S2 increased the number of single phosphorylated peptides in $\mathrm{Zr}$ IMAC (78\% x1 PO3), affecting Ti-IMAC as well $(64 \% \times 1$ PO3) to a higher extent than when using S3 (see Figure 3B and 5B). Moreover, Fe-IMAC mostly captured mono-phosphorylated peptides. Only 19\% of the phosphopeptides carried more than one phosphate-group per peptide (Figure 5B), whereas Std Ti-IMAC and Std Zr-IMAC had a more even distribution ( $52 \%$ and $60 \% \times 1$ PO3 respectively). Even though the distributions differ, the numbers of identified di- and multi-phosphorylated peptides was similar in Std/Zr-IMAC, Std/Ti-IMAC and S2/Ti-IMAC. They identified 1691, 1720 and 1597 multi-phosphorylated peptides respectively (Supplementary Figure 5).

Figure $5 \mathrm{C}$ shows the differences in bound phosphopeptides of all the conditions relative to S2/Zr-IMAC. Optimized Zr-IMAC was the best performing method in terms of total identifications (hence the negative values) binding $14 \%$ and 31\% more p-pep than Ti-IMAC in S2 and Std solvents respectively, and 19\% more than Fe-IMAC. Additionally, S2 improved the performance of Ti-IMAC with $24.4 \%$ more p-pep identified compared to Std/Ti-IMAC (Figure 5D), a greater difference than when solvent S3 was used (Figure 3C).

Collectively, all three methods contributed to the identification of a total of 7225 phosphopeptides (Figure 5E). Each method provided results and information that complemented the other methods. S2/Zr-IMAC and S2/TiIMAC identified altogether 5807 p-pep (80.4\% of the total), complementing Zr-IMAC alone by $11 \%$ and Ti-IMAC alone by $24 \%$ (Figure $5 E$ ). In combination with Fe-IMAC, S2/Zr-IMAC identified 92.5\% (6682) of the total number of identified p-pep, while Fe-IMAC alone covered 58.1\% albeit with many method-unique phosphopeptides (1418). This opens the possibility for complementary enrichment, e.g. utilising Fe-IMAC for monophosphorylated peptide enrichment and Zr-IMAC for multiple phosphorylated peptides.

Examining the uniquely found phosphopeptides for each method (S2/Zr-IMAC: 574, S2/Ti-IMAC: 543, Fe-IMAC: 1418, Figure 5E), Fe-IMAC HPLC showed a preference towards more basic sequences than the other two methods, as it recovered peptides with higher pl values (Supplementary Figure 8). Zr- and Ti-IMAC showed similar profiles of 


\section{Zr-IMAC for phosphopeptide enrichment in phosphoproteomics}

acidity and basicity, though Ti-IMAC bound more acidic phosphopeptides than Zr-IMAC. Peptide hydrophobicity was higher in Zr-IMAC than Ti- and Fe-IMAC, and Fe-IMAC identified shorter peptides than Zr-IMAC and Ti-IMAC (Supplementary Figure 8).

Method complementarity was also observed at the individual phosphoprotein level. For example, phosphorylation sites in a single protein were localized by either S2/Zr-IMAC, S2/Ti-IMAC or Fe-IMAC. As an illustration, human protein scribble homolog (UniProt ac. No. Q14160), a scaffold protein found in the plasma membrane of cells involved in morphogenesis regulation. A total of 12 high confidence phosphorylation sites (phosphoRS > 95\%) were localized in the protein. Four sites were found solely by S2/Zr-IMAC (S37, S853, S1348, S1508), one by S2/Ti-IMAC (S1306) and one by Fe-IMAC (S1448) (Supplementary Figure 7).

We investigated the differences in the bound phosphopeptides between binding solvents Std and S2 in Ti-IMAC and Zr-IMAC (Supplementary Figure 9), which presented very similar profiles to those of the previous experiments (Supplementary Figure 4). In this case, the optimized conditions recovered longer peptide sequences than the control, with Zr-IMAC having similar lengths and properties in both Std and S2. Ti-IMAC, on the other hand, showed more distinct differences, binding more acidic peptides with solvent S2 than with Std.

Finally, we looked at the number of identified phosphorylated proteins between the different methods and conditions (Supplementary Figure 10). Fe-IMAC HPLC identified the highest number of proteins compared to Zrand Ti-IMAC in Std solvent (1891, 1682 and 1456 identifications, respectively). However, when using solvent S2 both Zr-IMAC and Ti-IMAC identified 17\% more phosphoproteins each, with Zr-IMAC surpassing Fe-IMAC HPLC at 1965 identifications, again revealing the complementarity of these methods. 


\section{Zr-IMAC for phosphopeptide enrichment in phosphoproteomics}

\section{DISCUSSION}

Mass spectrometry-based phosphoproteomics is an important bioanalytical tool for investigating dynamic cell signalling processes and discover potential biomarkers for diseases, such as cancer and diabetes $[14,17,23,65]$. Therefore, it is imperative to develop efficient, sensitive and automated methods for enrichment of phosphopeptides in fast and reproducible analytical and computational workflows. Towards this goal we optimized Zr-IMAC in a magnetic bead format and demonstrated that Zr-IMAC is a reliable tool for large-scale phosphoproteome analysis.

We first investigated six solvent compositions for three types of magnetic microparticles (Zr-IMAC, Ti-IMAC and $\mathrm{TiO}_{2}$ ), and we found ideal conditions for phosphopeptide enrichment for each one. Next, we compared each material under standard and optimized conditions using 200ug of HepG2/C3A cell protein digest. The improved ZrIMAC enrichment captured the highest number of p-pep with 97\% selectivity, identifying $19 \%$ more p-pep than in standard conditions (Figures $3 \mathrm{~A}, 3 \mathrm{~B}$ and $3 \mathrm{C}$ ). We then proceeded to test Zr-IMAC and Ti-IMAC magnetic microparticles against Fe-IMAC HPLC based p-pep enrichment $[38,66]$, using both control and the optimized solvents. Compared to Fe-IMAC, our results revealed high selectivity of all magnetic microbeads based methods, greater coverage of multiphosphorylated peptides and, in the case of optimized Zr-IMAC, higher numbers of p-pep and phosphorylated proteins (Figures 5A, 5B, Supplementary Figure 10). In short, Zr-IMAC demonstrated to be on par with more popular enrichment methods and outperforming them with some optimization of enrichment conditions. Using magnetic microparticles allowed for faster and parallel workflows for processing samples. We could perform 16 magnetic particle-based enrichment experiments in parallel in one hour using manual sample processing, and with application of a magnetic handling station up to 96 samples can be processed in parallel in less than one hour[31, 67, 68].

Reducing the concentration of hydroxy acid in the binding solvent increased the number of identified phosphopeptides for all tested affinity materials (Figure $3 \mathrm{~A}$ and $3 \mathrm{C}$ ). Since $\mathrm{pH}$ and ionic strength of the mobile phase affect peptide retention [69], a possible explanation could be that the high concentration of glycolic acid 


\section{Zr-IMAC for phosphopeptide enrichment in phosphoproteomics}

$(1 \mathrm{M})$ in the solvent increased competition with the phosphate groups of the peptides, while optimized solvents all had lower concentrations of acid $(0.1 \mathrm{M})$, possibly reducing the effect of competition. This improvement in $\mathrm{p}$-pep recovery also affected phosphoprotein identification, where once again S2/Zr-IMAC outperformed the other condition (Supplementary Figure 2) without any significant differences in terms of protein localization in the cell (Supplementary Figure 3).

We observed a moderate increase in hydrophobic sequences when using the optimized solvents in $\mathrm{Zr}$ - and TiIMAC, as well as a large increase in acidic peptides for $\mathrm{TiO}_{2}$ (Figures $4 \mathrm{~B}$ and 4C, Supplementary Figure 4). This change in peptide properties could be related to the decrease of proton and hydroxy acid concentrations in solution. Weaker ionic strength and less competition for chelation could improve the diffusion of highly hydrophobic sequences to the aqueous phase where the electrophile metals are located [34]. Consequently, in Std solvent ( $5 \%$ TFA, $1 \mathrm{M} \mathrm{GA}$ ) these peptides would not bind efficiently to the metal cations and would be lost during the washing steps, explaining also why we could see lower numbers of monophosphorylated peptides under these conditions, being less hydrophilic than multiphosphorylated peptides.

As solvent S2 proved to enhance Zr-IMAC enrichment, we also evaluated its effect on Ti-IMAC. We further compared these magnetic materials with Fe-IMAC HPLC, a well-established method for phosphopeptide enrichment $[38,70,71]$. Even though we identified more phosphorylated proteins in Fe-IMAC than in Std/Zr-IMAC and Std/Ti-IMAC, optimized Zr-IMAC enrichment outperformed both Fe-IMAC and Ti-IMAC, identifying more phosphoproteins and p-pep with an excellent selectivity of over 90\% (Figure 5A, Supplemental figure 10). Moreover, the Fe-IMAC HPLC column revealed a bias towards monophosphorylated peptides and lower selectivity than the magnetic microparticles (Figures 5A and 5B), which, in contrast, they showed a more distributed binding of mono- and multi-phosphorylated peptides. Nevertheless, both Ti- and Zr-IMAC had a much higher preference to acidic sequences than Fe-IMAC. This behaviour could be explained by the strong interactivity of Ti4+ and Zr4+ with oxygen groups [52-54, 72], whereas the weaker Lewis acid Fe3+ could interact with other side-chain groups. 


\section{Zr-IMAC for phosphopeptide enrichment in phosphoproteomics}

Combining results obtained by using Zr-IMAC magnetic microparticles with Fe-IMAC HPLC, we were able to boost our p-pep numbers by $21 \%$ and identify $15 \%$ more phosphoproteins (Figure 5E, Supplementary Figure 10). We also observed complementarity of these enrichment methods in mapping multiple phosphorylation sites in individual proteins (Supplementary Figure 7). Our study, like others, highlights the importance of applying several enrichment strategies for comprehensive phosphoprotein analysis, since potentially valuable information can be missed when using only one method.

In conclusion, we demonstrated that Zr-IMAC magnetic microparticles are generally applicable to phosphopeptide enrichment in phosphoproteomics workflows and it performs on par, if not better, than currently used IMAC and MOAC techniques. We captured high numbers of p-pep with optimized sample loading solvent for Zr-IMAC while maintaining excellent selectivity. The Zr-IMAC magnetic microbead format complements currently used phosphopeptide enrichment methods and is easily automated using robotic sample handling. We conclude that $\mathrm{Zr}$ IMAC is widely applicable in functional phosphoproteomics studies and cell signalling research in biology and biomedicine.

\section{Acknowledgements}

This study was part of the activities of the EU Horizon 2020 Innovative Training Network (ITN) Biocapture (Grant agreement 722171). We thank Adelina Rogowska-Wrzesinska and Helle Frandsen for providing hepatocyte cells. Proteomics and mass spectrometry research at SDU is supported by generous grants to the VILLUM Center for Bioanalytical Sciences (VILLUM Foundation grant no. 7292, to O.N.J.) and PRO-MS: Danish National Mass Spectrometry Platform for Functional Proteomics (grant no. 5072-00007B, to O.N.J.). The proteomics and mass spectrometry research at CSIR is supported by generous grants from the Council of Scientific and Industrial Research (2017/2018 Thematic Programme grant no. TP-04-2018).

\section{Disclaimer/Disclosure}

Stoychev S. and Jordaan J. are employees of ReSyn Biosciences and have financial interests in the company. Govender I., and Naicker P., work on collaborative projects across CSIR and ReSyn Biosciences. 
Zr-IMAC for phosphopeptide enrichment in phosphoproteomics

\section{REFERENCES}

1. Cohen $\mathrm{P}$ (2001) The role of protein phosphorylation in human health and disease. The Sir Hans Krebs Medal Lecture. Eur J Biochem 268:5001-10. doi: 10.1046/j.0014-2956.2001.02473.x

2. Thorner J, Hunter T, Cantley LC and Sever R (2014) Signal transduction: From the atomic age to the post-genomic era. Cold Spring Harb Perspect Biol 6:a022913. doi:

10.1101/cshperspect.a022913

$3 . \quad$ Ubersax JA and Ferrell JE, Jr. (2007) Mechanisms of specificity in protein phosphorylation. Nat Rev Mol Cell Biol 8:530-41. doi: 10.1038/nrm2203

4. Blume-Jensen P and Hunter T (2001) Oncogenic kinase signalling. Nature 411:355-65. doi: $10.1038 / 35077225$

5. Locard-Paulet M, Lim L, Veluscek G, McMahon K, Sinclair J, van Weverwijk A, Worboys JD, Yuan $Y$, Isacke CM and Jorgensen C (2016) Phosphoproteomic analysis of interacting tumor and endothelial cells identifies regulatory mechanisms of transendothelial migration. Sci Signal 9:ra15. doi: 10.1126/scisignal.aac5820

6. Zanivan S, Meves A, Behrendt K, Schoof EM, Neilson L, Cox J, Tang HR, Kalna G, van Ree JH, van Deursen JM, Trempus CS, Machesky LM, Linding R, Wickstrom SA, Fassler R and Mann M (2013) In vivo SILAC-based proteomics reveals phosphoproteome changes during mouse skin carcinogenesis. Cell Rep 3:552-66. doi: 10.1016/j.celrep.2013.01.003

$7 . \quad$ Ortsater H, Grankvist N, Honkanen RE and Sjoholm A (2014) Protein phosphatases in pancreatic islets. J Endocrinol 221:R121-44. doi: 10.1530/JOE-14-0002

8. Scheuner D, Vander Mierde D, Song B, Flamez D, Creemers JW, Tsukamoto K, Ribick M, Schuit FC and Kaufman RJ (2005) Control of mRNA translation preserves endoplasmic reticulum function in beta cells and maintains glucose homeostasis. Nat Med 11:757-64. doi: 10.1038/nm1259

9. Tepper K, Biernat J, Kumar S, Wegmann S, Timm T, Hubschmann S, Redecke L, Mandelkow EM, Muller DJ and Mandelkow E (2014) Oligomer formation of tau protein hyperphosphorylated in cells. J Biol Chem 289:34389-407. doi: 10.1074/jbc.M114.611368

10. Ohno M (2014) Roles of elF2alpha kinases in the pathogenesis of Alzheimer's disease. Front Mol Neurosci 7:22. doi: 10.3389/fnmol.2014.00022

11. Gonzalez de Castro D, Clarke PA, Al-Lazikani B and Workman P (2013) Personalized cancer medicine: molecular diagnostics, predictive biomarkers, and drug resistance. Clin Pharmacol Ther 93:252-9. doi: 10.1038/clpt.2012.237

12. Dar AC and Shokat KM (2011) The evolution of protein kinase inhibitors from antagonists to agonists of cellular signaling. Annu Rev Biochem 80:769-95. doi: 10.1146/annurev-biochem-090308173656

13. Jensen ON (2006) Interpreting the protein language using proteomics. Nat Rev Mol Cell Biol 7:391-403. doi: 10.1038/nrm1939

14. Chan CY, Gritsenko MA, Smith RD and Qian WJ (2016) The current state of the art of quantitative phosphoproteomics and its applications to diabetes research. Expert Rev Proteomics 13:421-33. doi: 10.1586/14789450.2016.1164604

15. Roux PP and Thibault P (2013) The coming of age of phosphoproteomics--from large data sets to inference of protein functions. Mol Cell Proteomics 12:3453-64. doi: 10.1074/mcp.R113.032862

Zr-IMAC for phosphopeptide enrichment in phosphoproteomics 
16.

Gruhler A, Olsen JV, Mohammed S, Mortensen P, Faergeman NJ, Mann M and Jensen ON (2005) Quantitative phosphoproteomics applied to the yeast pheromone signaling pathway. Mol Cell Proteomics 4:310-27. doi: 10.1074/mcp.M400219-MCP200

17. Riley NM and Coon JJ (2016) Phosphoproteomics in the Age of Rapid and Deep Proteome Profiling. Anal Chem 88:74-94. doi: 10.1021/acs.analchem.5b04123

18. Tran TM, Friedman J, Qunaibi E, Baameur F, Moore RH and Clark RB (2004) Characterization of agonist stimulation of CAMP-dependent protein kinase and $\mathrm{G}$ protein-coupled receptor kinase phosphorylation of the beta2-adrenergic receptor using phosphoserine-specific antibodies. Mol Pharmacol 65:196-206. doi: 10.1124/mol.65.1.196

19. Rintamaki E, Salonen M, Suoranta UM, Carlberg I, Andersson B and Aro EM (1997) Phosphorylation of light-harvesting complex II and photosystem II core proteins shows different irradiance-dependent regulation in vivo. Application of phosphothreonine antibodies to analysis of thylakoid phosphoproteins. J Biol Chem 272:30476-82. doi: 10.1074/jbc.272.48.30476

20. Di Palma S, Zoumaro-Djayoon A, Peng M, Post H, Preisinger C, Munoz J and Heck AJ (2013) Finding the same needles in the haystack? A comparison of phosphotyrosine peptides enriched by immuno-affinity precipitation and metal-based affinity chromatography. J Proteomics 91:331-7. doi: 10.1016/j.jprot.2013.07.024

21. Bian Y, Li L, Dong M, Liu X, Kaneko T, Cheng K, Liu H, Voss C, Cao X, Wang Y, Litchfield D, Ye M, Li SS and Zou H (2016) Ultra-deep tyrosine phosphoproteomics enabled by a phosphotyrosine superbinder. Nat Chem Biol 12:959-966. doi: 10.1038/nchembio.2178

22. Thingholm TE, Jensen ON and Larsen MR (2009) Analytical strategies for phosphoproteomics. Proteomics 9:1451-68. doi: 10.1002/pmic.200800454

23. Beltran L and Cutillas PR (2012) Advances in phosphopeptide enrichment techniques for phosphoproteomics. Amino Acids 43:1009-24. doi: 10.1007/s00726-012-1288-9

24. Bllaci L, Torsetnes SB, Wierzbicka C, Shinde S, Sellergren B, Rogowska-Wrzesinska A and Jensen ON (2017) Phosphotyrosine Biased Enrichment of Tryptic Peptides from Cancer Cells by Combining pY-MIP and TiO2 Affinity Resins. Analytical Chemistry 89:11332-11340. doi:

10.1021/acs.analchem.7b02091

25. Stensballe A, Andersen S and Jensen ON (2001) Characterization of phosphoproteins from electrophoretic gels by nanoscale Fe(III) affinity chromatography with off-line mass spectrometry analysis. Proteomics 1:207-22. doi: 10.1002/1615-9861(200102)1:2<207::AID-PROT207>3.0.CO;2-3 26. Feng S, Ye M, Zhou H, Jiang X, Jiang X, Zou H and Gong B (2007) Immobilized zirconium ion affinity chromatography for specific enrichment of phosphopeptides in phosphoproteome analysis. Mol Cell Proteomics 6:1656-65. doi: 10.1074/mcp.T600071-MCP200

27. Zhou H, Ye M, Dong J, Corradini E, Cristobal A, Heck AJ, Zou H and Mohammed S (2013) Robust phosphoproteome enrichment using monodisperse microsphere-based immobilized titanium (IV) ion affinity chromatography. Nat Protoc 8:461-80. doi: 10.1038/nprot.2013.010

28. Posewitz MC and Tempst P (1999) Immobilized gallium(III) affinity chromatography of phosphopeptides. Anal Chem 71:2883-92. doi: 10.1021/ac981409y

29. Neville DC, Rozanas CR, Price EM, Gruis DB, Verkman AS and Townsend RR (1997) Evidence for phosphorylation of serine 753 in CFTR using a novel metal-ion affinity resin and matrixassisted laser desorption mass spectrometry. Protein Sci 6:2436-45. doi: 10.1002/pro.5560061117 
30.

de Graaf EL, Giansanti P, Altelaar AF and Heck AJ (2014) Single-step enrichment by Ti4+IMAC and label-free quantitation enables in-depth monitoring of phosphorylation dynamics with high reproducibility and temporal resolution. Mol Cell Proteomics 13:2426-34. doi:

10.1074/mcp.0113.036608

31. Tape CJ, Worboys JD, Sinclair J, Gourlay R, Vogt J, McMahon KM, Trost M, Lauffenburger DA, Lamont DJ and Jorgensen C (2014) Reproducible automated phosphopeptide enrichment using magnetic TiO2 and Ti-IMAC. Anal Chem 86:10296-302. doi: 10.1021/ac5025842

32. Huang J, Dong J, Shi X, Chen Z, Cui Y, Liu X, Ye M and Li L (2019) Dual-Functional Titanium(IV) Immobilized Metal Affinity Chromatography Approach for Enabling Large-Scale Profiling of Protein Mannose-6-Phosphate Glycosylation and Revealing Its Predominant Substrates. Anal Chem 91:11589-11597. doi: 10.1021/acs.analchem.9b01698

33. Thingholm TE and Larsen MR (2016) The Use of Titanium Dioxide for Selective Enrichment of Phosphorylated Peptides. Methods Mol Biol 1355:135-46. doi: 10.1007/978-1-4939-3049-4_9 34. Larsen MR, Thingholm TE, Jensen ON, Roepstorff P and Jorgensen TJ (2005) Highly selective enrichment of phosphorylated peptides from peptide mixtures using titanium dioxide microcolumns. Mol Cell Proteomics 4:873-86. doi: 10.1074/mcp.T500007-MCP200 35. Li Y, Liu Y, Tang J, Lin H, Yao N, Shen X, Deng C, Yang P and Zhang X (2007) Fe3O4@Al2O3 magnetic core-shell microspheres for rapid and highly specific capture of phosphopeptides with mass spectrometry analysis. J Chromatogr A 1172:57-71. doi: 10.1016/j.chroma.2007.09.062

36. Han L, Shan Z, Chen D, Yu X, Yang P, Tu B and Zhao D (2008) Mesoporous Fe2O3 microspheres: rapid and effective enrichment of phosphopeptides for MALDI-TOF MS analysis. J Colloid Interface Sci 318:315-21. doi: 10.1016/j.jcis.2007.10.026

37. Kweon HK and Hakansson K (2006) Selective zirconium dioxide-based enrichment of phosphorylated peptides for mass spectrometric analysis. Anal Chem 78:1743-9. doi: 10.1021/ac0522355

38. Ruprecht B, Koch H, Medard G, Mundt M, Kuster B and Lemeer S (2015) Comprehensive and reproducible phosphopeptide enrichment using iron immobilized metal ion affinity chromatography (Fe-IMAC) columns. Mol Cell Proteomics 14:205-15. doi: 10.1074/mcp.M114.043109

39. Yue $X$, Schunter A and Hummon AB (2015) Comparing multistep immobilized metal affinity chromatography and multistep TiO2 methods for phosphopeptide enrichment. Anal Chem 87:8837-44. doi: 10.1021/acs.analchem.5b01833

40. Matheron L, van den Toorn H, Heck AJ and Mohammed S (2014) Characterization of biases in phosphopeptide enrichment by $\mathrm{Ti}(4+)$-immobilized metal affinity chromatography and $\mathrm{TiO} 2$ using a massive synthetic library and human cell digests. Anal Chem 86:8312-20. doi: 10.1021/ac501803z

41. Kweon HK and Andrews PC (2013) Quantitative analysis of global phosphorylation changes with high-resolution tandem mass spectrometry and stable isotopic labeling. Methods 61:2519. doi: 10.1016/j.ymeth.2013.04.010

42. Zhou H, Xu S, Ye M, Feng S, Pan C, Jiang X, Li X, Han G, Fu Y and Zou H (2006) Zirconium phosphonate-modified porous silicon for highly specific capture of phosphopeptides and MALDI-TOF MS analysis. J Proteome Res 5:2431-7. doi: 10.1021/pr060162f

43. Wei J, Zhang Y, Wang J, Tan F, Liu J, Cai Y and Qian X (2008) Highly efficient enrichment of phosphopeptides by magnetic nanoparticles coated with zirconium phosphonate for phosphoproteome analysis. Rapid Commun Mass Spectrom 22:1069-80. doi: 10.1002/rcm.3485

44. Wang H, Duan J, Yu H, Zhao L, Liang Y, Shan Y, Zhang L, Liang Z and Zhang Y (2011) Monoliths with immobilized zirconium ions for selective enrichment of phosphopeptides. J Sep Sci 34:2113-21. doi: $10.1002 /$ jssc. 201100168 
45. Zhao PX, Guo XF, Wang H, Qi CB, Xia HS and Zhang HS (2012) Zirconium arsenatemodified silica nanoparticles for specific capture of phosphopeptides and direct analysis by matrixassisted laser desorption/ionization mass spectrometry. Anal Bioanal Chem 402:1041-56. doi: 10.1007/s00216-011-5547-5

46. Zhang L, Xu J, Sun L, Ma J, Yang K, Liang Z, Zhang L and Zhang Y (2011) Zirconium oxide aerogel for effective enrichment of phosphopeptides with high binding capacity. Anal Bioanal Chem 399:3399-405. doi: 10.1007/s00216-011-4657-4

47. Vilasi A, Fiume I, Pace P, Rossi M and Pocsfalvi G (2013) Enrichment specificity of micro and nano-sized titanium and zirconium dioxides particles in phosphopeptide mapping. J Mass Spectrom 48:1188-98. doi: 10.1002/jms.3254

48. Sugiyama N, Masuda T, Shinoda K, Nakamura A, Tomita M and Ishihama Y (2007) Phosphopeptide enrichment by aliphatic hydroxy acid-modified metal oxide chromatography for nanoLC-MS/MS in proteomics applications. Mol Cell Proteomics 6:1103-9. doi: 10.1074/mcp.T600060MCP200

49. Mazanek M, Roitinger E, Hudecz O, Hutchins JR, Hegemann B, Mitulovic G, Taus T, Stingl C, Peters JM and Mechtler K (2010) A new acid mix enhances phosphopeptide enrichment on titaniumand zirconium dioxide for mapping of phosphorylation sites on protein complexes. J Chromatogr $B$ Analyt Technol Biomed Life Sci 878:515-24. doi: 10.1016/j.jchromb.2009.12.017

50. Kelly RT, Page JS, Luo Q, Moore RJ, Orton DJ, Tang K and Smith RD (2006) Chemically etched open tubular and monolithic emitters for nanoelectrospray ionization mass spectrometry. Anal Chem 78:7796-801. doi: 10.1021/ac061133r

51. Wang ZG, Lv N, Bi WZ, Zhang JL and Ni JZ (2015) Development of the affinity materials for phosphorylated proteins/peptides enrichment in phosphoproteomics analysis. ACS Appl Mater Interfaces 7:8377-92. doi: 10.1021/acsami.5b01254

52. Zhao PX, Zhao Y, Guo XF, Wang H and Zhang HS (2011) Isolation of phosphopeptides using zirconium-chlorophosphonazo chelate-modified silica nanoparticles. J Chromatogr A 1218:2528-39. doi: 10.1016/j.chroma.2011.02.071

53. Han G, Ye M and Zou H (2008) Development of phosphopeptide enrichment techniques for phosphoproteome analysis. Analyst 133:1128-38. doi: 10.1039/b806775a

54. Stanghellini PL, Boccaleri E, Diana E, Alberti G and Vivani R (2004) Vibrational study of some layered structures based on titanium and zirconium phosphates. Inorg Chem 43:5698-703. doi: 10.1021/ic049565c

55. Jensen SS and Larsen MR (2007) Evaluation of the impact of some experimental procedures on different phosphopeptide enrichment techniques. Rapid Commun Mass Spectrom 21:3635-45. doi: 10.1002/rcm.3254

56. Wrzesinski K, Rogowska-Wrzesinska A, Kanlaya R, Borkowski K, Schwammle V, Dai J, Joensen KE, Wojdyla K, Carvalho VB and Fey SJ (2014) The cultural divide: exponential growth in classical 2D and metabolic equilibrium in 3D environments. PLoS One 9:e106973. doi:

10.1371/journal.pone.0106973

57. Heissel S, Bunkenborg J, Kristiansen MP, Holmbjerg AF, Grimstrup M, Mortz E, Kofoed T and Hojrup P (2018) Evaluation of spectral libraries and sample preparation for DIA-LC-MS analysis of host cell proteins: A case study of a bacterially expressed recombinant biopharmaceutical protein. Protein Expr Purif 147:69-77. doi: 10.1016/j.pep.2018.03.002 
58. Kall L, Canterbury JD, Weston J, Noble WS and MacCoss MJ (2007) Semi-supervised learning for peptide identification from shotgun proteomics datasets. Nat Methods 4:923-5. doi: $10.1038 /$ nmeth1113

59. Taus T, Kocher T, Pichler P, Paschke C, Schmidt A, Henrich C and Mechtler K (2011) Universal and confident phosphorylation site localization using phosphoRS. J Proteome Res 10:5354-62. doi: $10.1021 /$ pr200611n

60. Kyte J and Doolittle RF (1982) A simple method for displaying the hydropathic character of a protein. J Mol Biol 157:105-32. doi: 10.1016/0022-2836(82)90515-0

61. Kozlowski LP (2016) IPC - Isoelectric Point Calculator. Biol Direct 11:55. doi: 10.1186/s13062-016-0159-9

62. Peri S, Steen H and Pandey A (2001) GPMAW--a software tool for analyzing proteins and peptides. Trends Biochem Sci 26:687-9. doi: 10.1016/s0968-0004(01)01954-5

63. Vizcaino JA, Cote RG, Csordas A, Dianes JA, Fabregat A, Foster JM, Griss J, Alpi E, Birim M, Contell J, O'Kelly G, Schoenegger A, Ovelleiro D, Perez-Riverol Y, Reisinger F, Rios D, Wang R and Hermjakob H (2013) The PRoteomics IDEntifications (PRIDE) database and associated tools: status in 2013. Nucleic Acids Res 41:D1063-9. doi: 10.1093/nar/gks1262

64. $\quad$ Mi H, Muruganujan A, Ebert D, Huang X and Thomas PD (2019) PANTHER version 14: more genomes, a new PANTHER GO-slim and improvements in enrichment analysis tools. Nucleic Acids Res 47:D419-D426. doi: 10.1093/nar/gky1038

65. Mann M, Ong SE, Gronborg M, Steen H, Jensen ON and Pandey A (2002) Analysis of protein phosphorylation using mass spectrometry: deciphering the phosphoproteome. Trends Biotechnol 20:261-8.

66. Potel CM, Lin MH, Heck AJR and Lemeer S (2018) Defeating Major Contaminants in Fe(3+)- Immobilized Metal Ion Affinity Chromatography (IMAC) Phosphopeptide Enrichment. Mol Cell Proteomics 17:1028-1034. doi: 10.1074/mcp.TIR117.000518

67. Leutert M, Rodriguez-Mias RA, Fukuda NK and Villen J (2019) R2-P2 rapid-robotic phosphoproteomics enables multidimensional cell signaling studies. Mol Syst Biol 15:e9021. doi: $10.15252 / \mathrm{msb} .20199021$

68. Bekker-Jensen DB, Martinez-Val A, Steigerwald S, Ruther P, Fort KL, Arrey TN, Harder A, Makarov A and Olsen JV (2020) A Compact Quadrupole-Orbitrap Mass Spectrometer with FAIMS Interface Improves Proteome Coverage in Short LC Gradients. Mol Cell Proteomics 19:716-729. doi: 10.1074/mcp.TIR119.001906

69. Nawrocki J, Dunlap C, McCormick A and Carr PW (2004) Part I. Chromatography using ultra-stable metal oxide-based stationary phases for HPLC. J Chromatogr A 1028:1-30. doi:

10.1016/j.chroma.2003.11.052

70. Lam C, Ferguson ID, Mariano MC, Lin YT, Murnane M, Liu H, Smith GA, Wong SW, Taunton J, Liu JO, Mitsiades CS, Hann BC, Aftab BT and Wiita AP (2018) Repurposing tofacitinib as an antimyeloma therapeutic to reverse growth-promoting effects of the bone marrow microenvironment. Haematologica 103:1218-1228. doi: 10.3324/haematol.2017.174482

71. Potel CM, Lin MH, Heck AJR and Lemeer S (2018) Widespread bacterial protein histidine phosphorylation revealed by mass spectrometry-based proteomics. Nat Methods 15:187-190. doi: 10.1038/nmeth.4580

72. Nonglaton G, Benitez IO, Guisle I, Pipelier M, Leger J, Dubreuil D, Tellier C, Talham DR and Bujoli B (2004) New approach to oligonucleotide microarrays using zirconium phosphonate-modified surfaces. J Am Chem Soc 126:1497-502. doi: 10.1021/ja039072r 
A

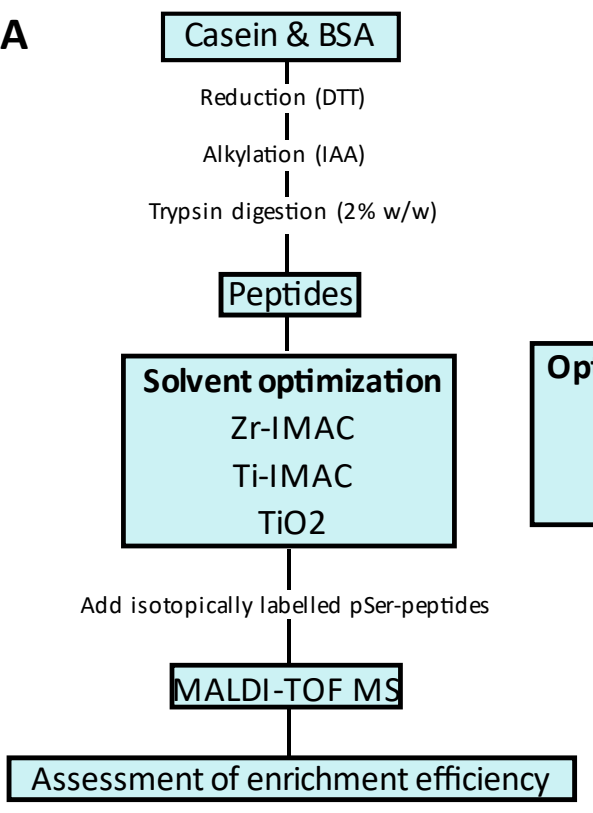

B

Human HepG2/C3A hepatocyte cells

Lysis (1\%SDC, $10 \mathrm{mM}$ TCEP, 40mM CAA)

Proteins

Trypsin digestion $(2 \% \mathrm{w} / \mathrm{w})$

C18 De-salting

Peptides

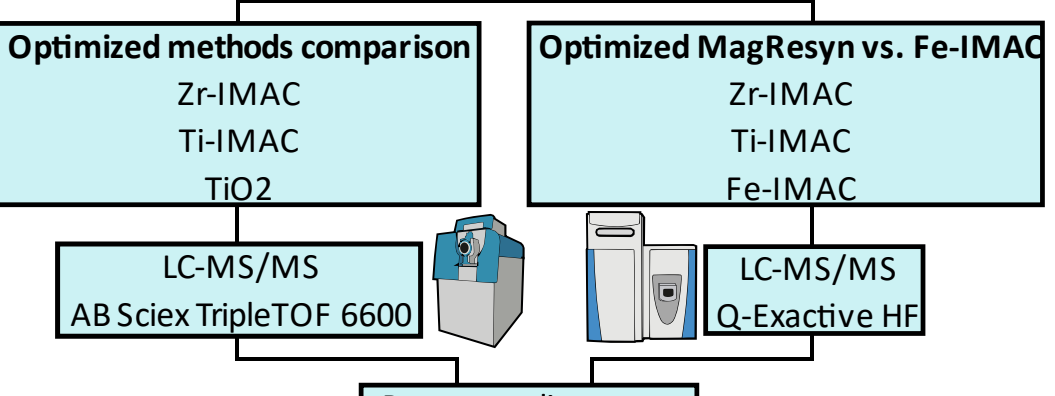

Proteome discoverer

Mascot

Comparative phosphopeptide analysis

Figure 1. Schematic description of the workflows. (A) Selection of enrichment solvent conditions for each bead chemistry using simple peptide digests and spiking them with three isotopically labelled peptides for MS1 relative quantification of phosphopeptides. (B) Test of optimal conditions against complex peptide mixtures. First, the respective optimal solvents for $\mathrm{Zr}-\mathrm{IMAC}, \mathrm{Ti}-\mathrm{IMAC}$ and $\mathrm{TiO} 2$ were evaluated (left branch). The best performing solvent and microparticles were afterwards compared with Fe-IMAC HPLC enrichment (right branch). 
bioRxiv preprint doi: https://doi.org/10.1101/2020.04.13.038810; this version posted April 13, 2020. The copyright holder for this preprint (which was not certified by peer review) is the author/funder, who has granted bioRxiv a license to display the preprint in perpetuity. It is made available under aCC-BY-NC-ND 4.0 International license.

\section{Zr-IMAC for phosphopeptide enrichment in phosphoproteomics}
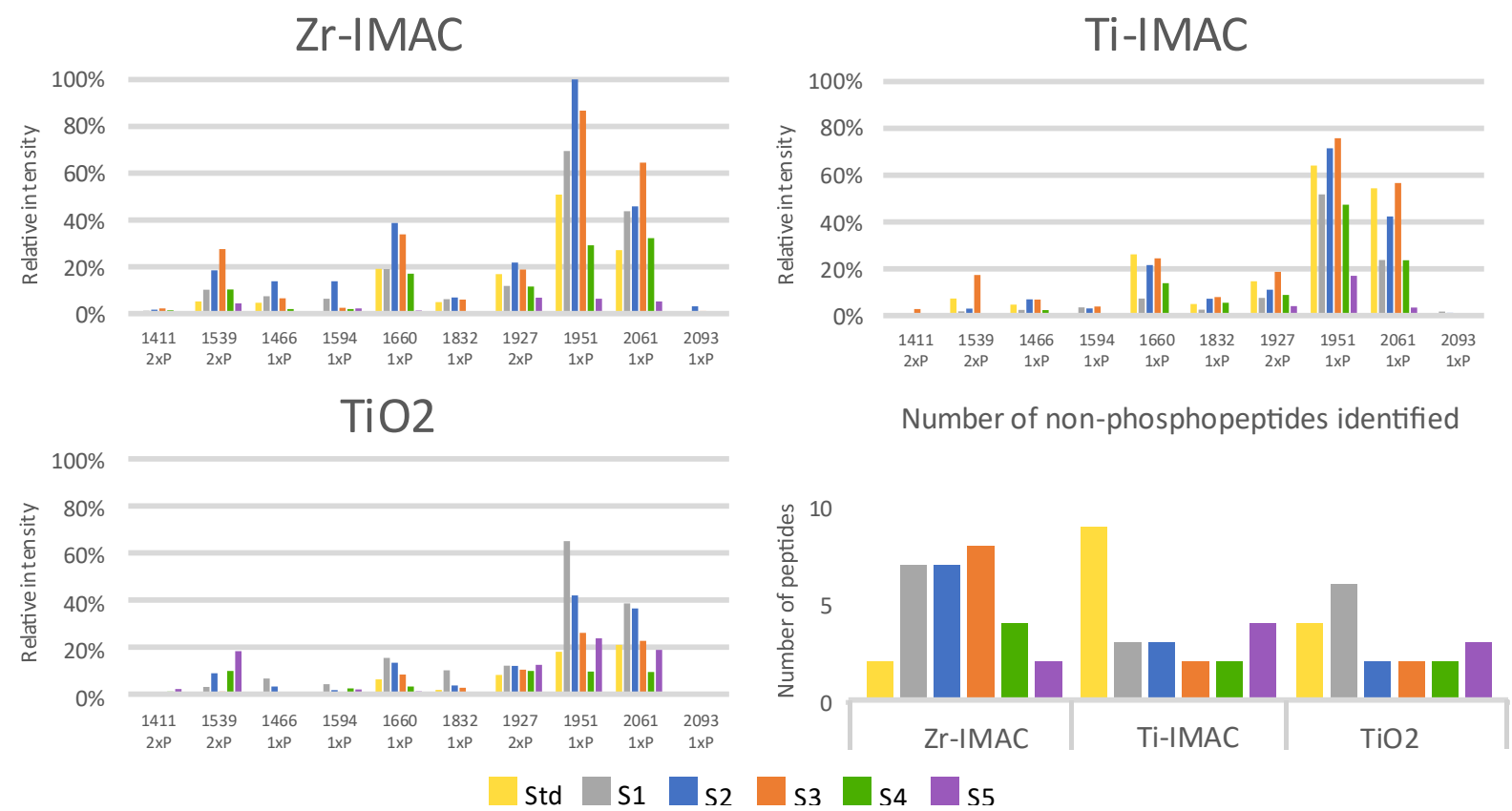

Figure 2. Phosphopeptide enrichment efficiency of each condition based on the relative intensity of the unlabelled phosphopeptides vs. the most intense stable isotope labelled phosphopeptide ( $\mathrm{m} / \mathrm{z}$ 1958). Bottom right, number of non-phosphorylated peptides identified for each condition (Refer to table 1 to see solvent compositions). 


\section{Zr-IMAC for phosphopeptide enrichment in phosphoproteomics}

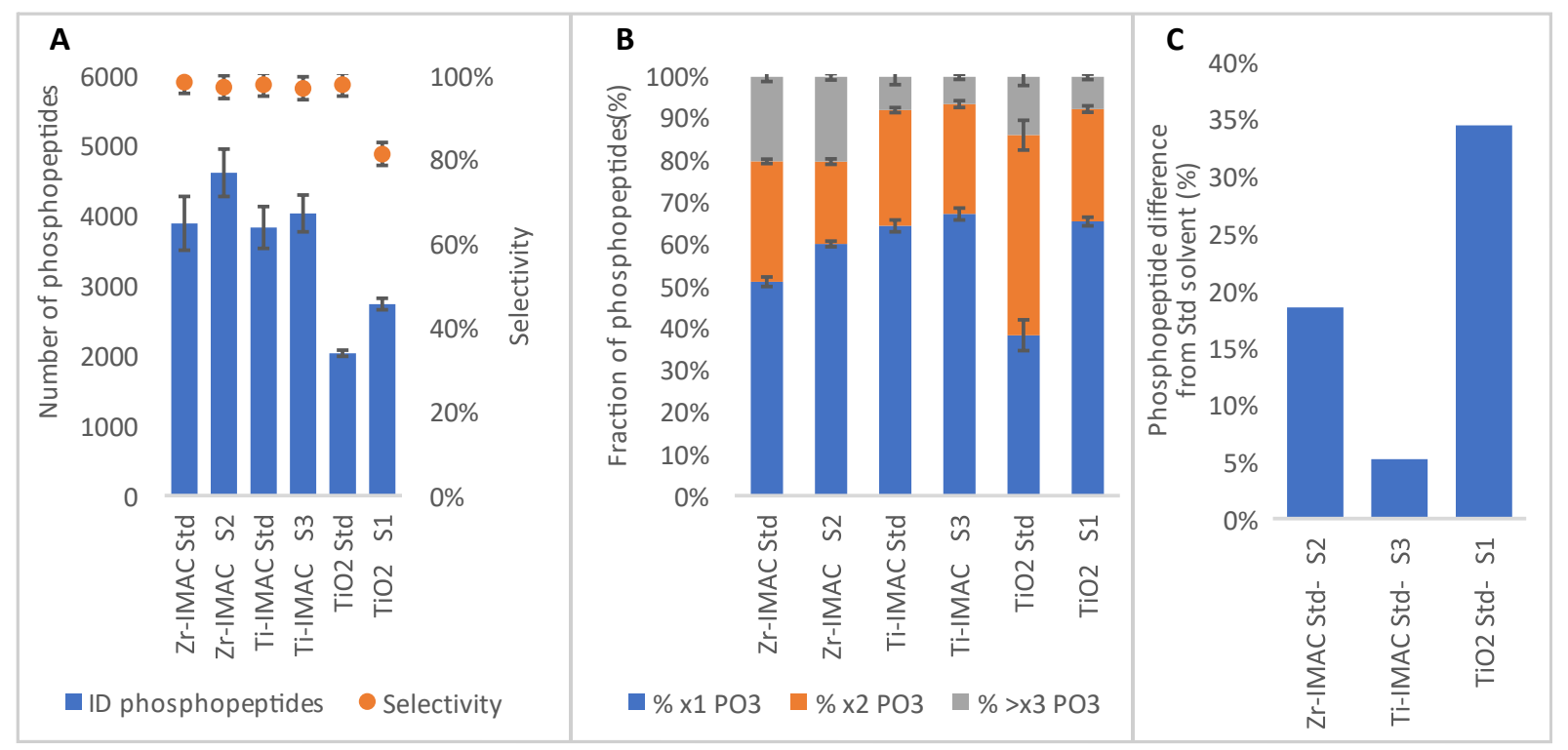

Figure 3. Phosphopeptide (p-pep) profiling of MagReSyn ${ }^{\circledR}$ microparticles by LC-MS/MS on AB Sciex TripleTOF 6600.

(A) Number of p-pep identified for each condition (blue bars) and the selectivity of each enrichment (orange dots).

(B) Mono- (blue), di- (orange) and multi-phosphorylated (grey) peptide distribution in each condition. (C)

Difference in percentage of identified p-pep between the optimized solvent $(\mathrm{S} 1, \mathrm{~S} 2, \mathrm{~S} 3)$ and the standard (Std). 


\section{Zr-IMAC for phosphopeptide enrichment in phosphoproteomics}

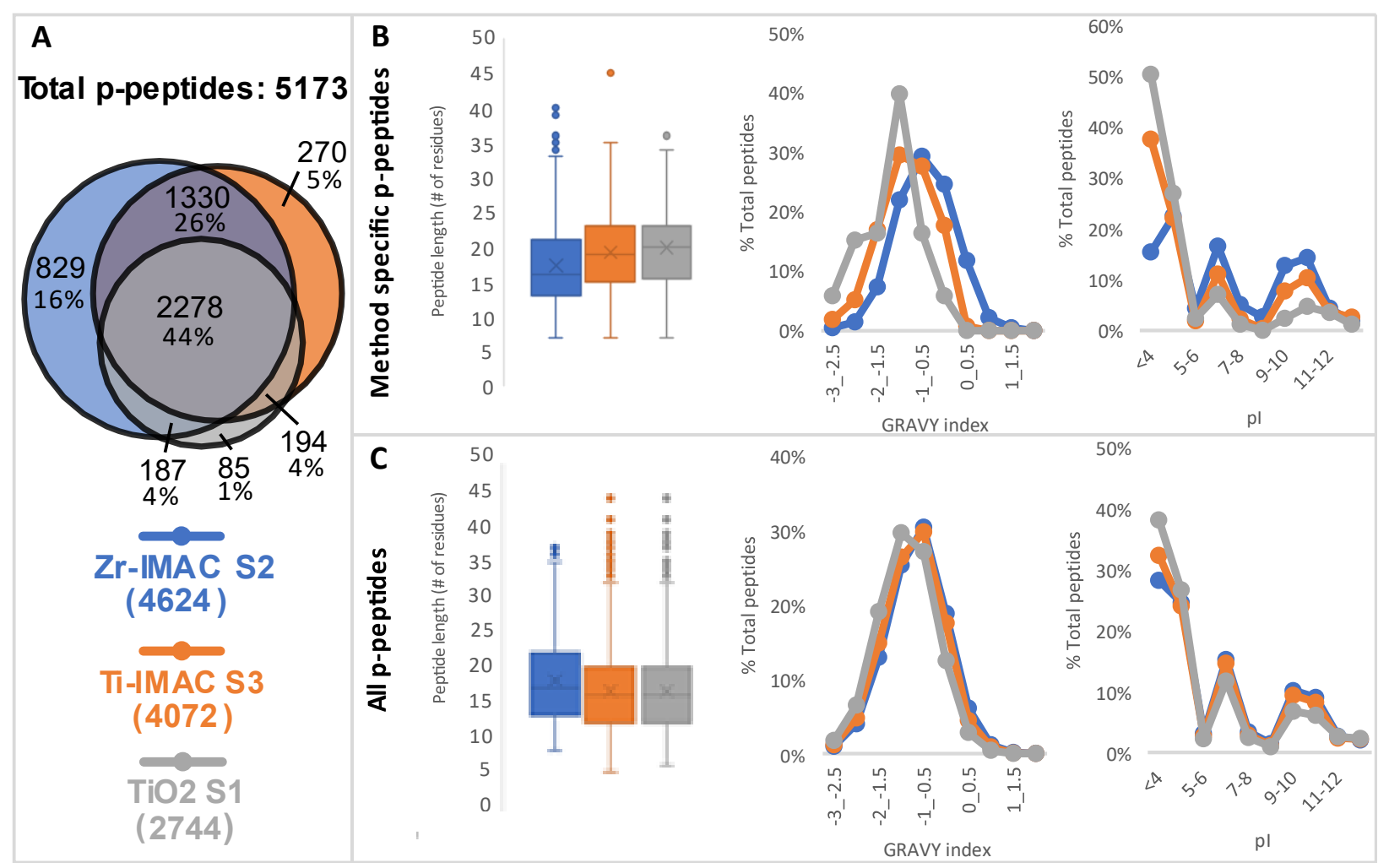

Figure 4. Feature analysis of phosphopeptides (p-pep) identified in the optimized methods. A) At the top, Venn diagram of the $p$-pep identified by each method (the number of $p$-pep and percentage relative to total). Combination of p-pep identified (5173). At the bottom, number of identified p-pep in each method: 4624 (S2/ZrIMAC, blue), 4072 (S3/Ti-IMAC, orange) and 2744 (S1/ $\mathrm{TiO}_{2}$, grey). B) Feature analysis of enriched p-pep found only in one of the methods: S2/Zr-IMAC (829 p-pep, blue), S3/Ti-IMAC (270 p-pep, orange) and S1/ TiO 2 (85 p-pep, grey). From left to right, boxplot of peptide length distribution with mean marked as an X, GRAVY indexes distribution and $\mathrm{pl}$ values distribution. Lower values of GRAVY index represent less hydrophobicity. C) Feature analysis of all enriched p-pep from S2/Zr-IMAC (4624 p-pep, blue), S3/Ti-IMAC (4072 p-pep, orange) and S1/ TiO 2 (2744 p-pep, grey). From left to right, boxplot of peptide length distribution with mean marked as an X, GRAVY indexes distribution and $\mathrm{pl}$ values distribution. 

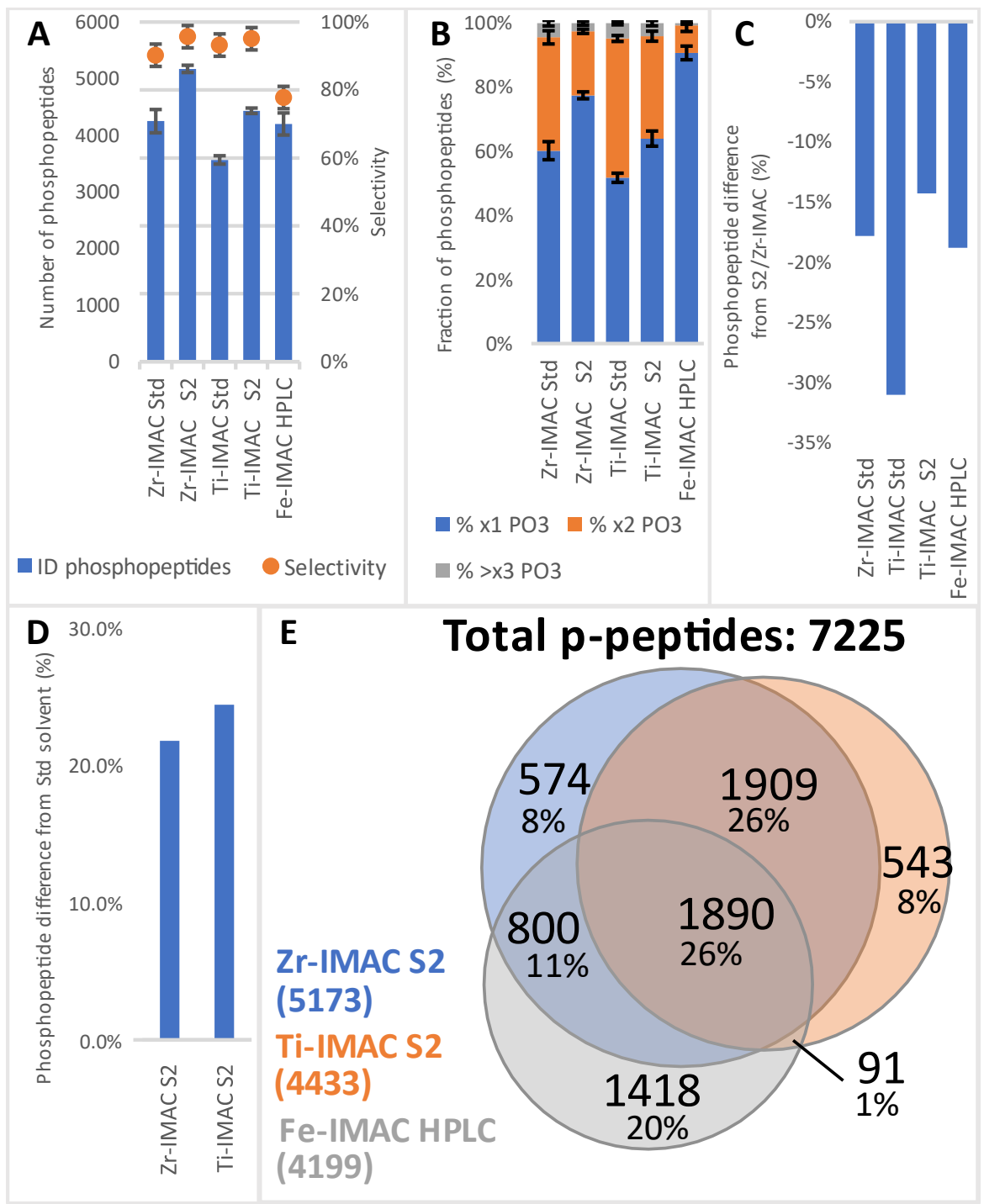

Figure 5. Phosphopeptide (p-pep) profiling of MagReSyn ${ }^{\circledR}$ microparticles by LC-MS/MS on Q Exactive HF. (A) Number of p-pep identified for each condition (blue bars) and the selectivity of each enrichment (orange dots). (B) Mono (blue), di (orange) and multiphosphorylated (grey) peptide distribution in each condition. (C) Differences in percentage of identified p-pep in each condition compared to the optimized S2/Zr-IMAC enrichment method. (D) Differences in percentage of identified p-pep between the optimized solvent (S2) and the standard (Std). (E) Venn diagram of identified p-pep from S2/Zr-IMAC (blue), S2/Ti-IMAC (orange) and Fe-IMAC (grey). 